\title{
QUEEN'S
UNIVERSITY
BELFAST
}

\section{Management of public water supply to reduce power cost and improve wind power uptake}

Kernan, R., Liu, X. A., McLoone, S., \& Fox, B. (2016). Management of public water supply to reduce power cost and improve wind power uptake. In 2016 IEEE 16th International Conference on Environment and Electrical Engineering (EEEIC) [7555810] Institute of Electrical and Electronics Engineers Inc.. https://doi.org/10.1109/EEEIC.2016.7555810

Published in:

2016 IEEE 16th International Conference on Environment and Electrical Engineering (EEEIC)

Document Version:

Peer reviewed version

Queen's University Belfast - Research Portal:

Link to publication record in Queen's University Belfast Research Portal

Publisher rights

(c) 2016 IEEE. Personal use of this material is permitted. Permission from IEEE must be obtained for all other uses, in any current or future media, including reprinting/republishing this material for advertising or promotional purposes, creating new collective works, for resale or redistribution to servers or lists, or reuse of any copyrighted component of this work in other works

\section{General rights}

Copyright for the publications made accessible via the Queen's University Belfast Research Portal is retained by the author(s) and / or other copyright owners and it is a condition of accessing these publications that users recognise and abide by the legal requirements associated with these rights.

Take down policy

The Research Portal is Queen's institutional repository that provides access to Queen's research output. Every effort has been made to ensure that content in the Research Portal does not infringe any person's rights, or applicable UK laws. If you discover content in the Research Portal that you believe breaches copyright or violates any law, please contact openaccess@qub.ac.uk. 


\section{Management of public water supply to reduce energy cost and improve wind power uptake}

\author{
Rónán Kernan \\ Queen's University Belfast \\ Northern Ireland
}

\author{
Xueqin (Amy) Liu \\ Queen's University Belfast \\ Northern Ireland
}

\author{
Seán McLoone \\ Queen's University Belfast \\ Northern Ireland
}

\author{
Brendan Fox \\ Queen's University Belfast \\ Northern Ireland
}

\begin{abstract}
This paper presents a study on the implementation of Real-Time Pricing (RTP) based Demand Side Management (DSM) of water pumping at a clean water pumping station in Northern Ireland, with the intention of minimising electricity costs and maximising the usage of electricity from wind generation. A Genetic Algorithm (GA) was used to create pumping schedules based on system constraints and electricity tariff scenarios. Implementation of this method would allow the water network operator to make significant savings on electricity costs while also helping to mitigate the variability of wind generation.
\end{abstract}

Keywords-Demand Side Management, Real Time Pricing, Genetic Algorithms, Wind Power, optimisation, water pumping

\section{INTRODUCTION}

The island of Ireland is heavily dependent on imports to meet its energy needs. In 2007, imported fuel accounted for $91 \%$ of all energy consumption [1]. Ireland is also committed to significant reductions in carbon emissions from power generation. Ireland has a large wind resource and as such significant investment has been made in wind power [2]. Wind power penetration had reached $16.4 \%$ of all power generation by 2014 , with a government target to reach $40 \%$ by 2020 [3].

This poses significant problems for the operation of the Irish power system (maintained by Eirgrid in the Republic of Ireland and SONI in Northern Ireland). Wind power, being dependent on the wind itself, is not dispatchable by the system operator, save to curtail its output. Curtailment currently occurs when System Non-Synchronous Penetration (SNSP) - primarily wind but also including solar power and interconnectors - exceeds $50 \%$ of total generation in order to maintain a minimum level of inertia on the system [5] [6]. Curtailment has negative consequences for the economics of wind generation, and is lost energy that has to be replaced by other generation, usually fossil-fired. Any mitigation of curtailment would reduce system costs as it would reduce the demand for low-merit and high-carbon generation.

Wind generation is highly variable. Power system scheduling uses wind forecasting to estimate generation which, although usually accurate in predicting the magnitude of wind, often incorrectly predicts its timing. Lacking large-scale energy storage (beyond the Turlough Hill pumped storage hydroelectric facility which can provide approx. $1750 \mathrm{MWh}$ ), the Irish grid uses fast-responding gas-powered generation to maintain generation levels. The traditional model of supply-side management, where generators alter their output to meet the load, has severe limitations when dealing with large quantities of variable generation such as wind power.

By having a measure of control over the timing and magnitude of load, the uncertainty and variability of wind power could be mitigated. Such Demand-Side Management (DSM) can take a number of forms, whether it be peak shaving (reducing maximum demand) or load shifting (altering the timing of the demand, but maintaining or increasing the volume). Effective DSM would reduce the need to invest in large-scale energy storage systems and reduce peak demand. Load could be scheduled to coincide as much as possible with periods of cheaper electricity, often due to high wind power.

Some loads are well suited to control of their power consumption without adversely impacting end-user demand. Such loads include domestic water heating, refrigeration [7] and electric vehicle charging. Municipal water supply has also been highlighted as a load with significant potential for DSM [8].

Water for public consumption is traditionally sourced from reservoirs in catchment areas, treated, then pumped to service reservoirs near centres of population. Water supply networks are energy intensive, consuming approximately $3-4 \%$ of all electricity [9], evenly split between clean water treatment and supply, and wastewater pumping and treatment [10].

Clean water pumping is the most obviously flexible component of water supply, representing $0.5-1 \%$ of total demand on the power system. Pumps are run to ensure level constraints in supply and service reservoirs are met. As long as water levels are kept within these limits, and system pressure constraints are not violated, there is relative freedom in the timing of pumping [11]. This can allow the water utility to minimise electricity costs based on variations in the wholesale price. This has been investigated in previous work, where it was shown that Northern Ireland Water (NIW) could make significant savings on electricity costs by implementation of price-based pumping optimisation [12]. Costs would be minimised when a Real Time Pricing (RTP) tariff (reflecting the actual wholesale cost, or System Marginal Price [SMP], of generating electricity) was used, a conclusion echoed in [13]. In the Irish Single Electricity Market (SEM), an 'Ex-Ante' 
forecast (EA1) of SMP is made available to market participants at 11:00 $\mathrm{h}$ one day in advance (D-1) and it is on this basis that pumping could be scheduled.

Wind generation has a marginal cost of zero. Significant wind penetration reduces the requirement for low-merit generation and thus reduces SMP. Since there should thus be a correlation between high wind penetrations and low SMP, it follows that by maximising load during low SMP periods, curtailment would be reduced and the amount of wind generation allowed within the SNSP limit would increase.

The aims of this investigation were twofold:

1) To understand the potential cost savings possible for a water utility by scheduling on the basis of RTP based on SMP forecasting.

2) To investigate the effectiveness of forecast SMP as a price signal for DSM in the context of maximising the uptake of wind generation.

\section{System Modelled}

In this research, the system modelled was scheduled on the basis of historical tariff data for the periods April 2012 March 2013, April 2013 - March 2014 and April 2014 - March 2015, with the aim of minimising electricity costs. Full-year electricity costs for each optimisation were compared with one another for the same period. The average wind power penetration and generation magnitude for the time periods during which the pumps were operating was measured, and compared with the averages for generation for all intervals.

The basic system modelled forms part of the NIW network. All information on the system was taken from a spreadsheet provided by NIW with data obtained from the SCADA (supervisory control and data acquisition) system. Water demand data were provided by NIW for the period 1 April 2012 to 30 March 2013. These data were then duplicated and used for the same dates in 2013 - 2014 and 2014 - 2015.

The system configuration is as follows ( Fig. 1). Two supply reservoirs are supplied by water from a treatment plant. From these reservoirs, water is pumped through a pumping station to a service reservoir, from which water is supplied to consumers. In the pumping station are three fixed-speed pumps - two duty and one standby. The two duty pumps operate simultaneously. Water demand varies similarly to electricity demand and in this case varied between 5 and $7 \mathrm{Ml}$ per day. The flow rate from the water treatment plant to the supply reservoir was allowed to vary by no more than $2.5 \%$ in each interval - this is because the chemical processes that occur in water treatment require a relatively constant flow of water to work efficiently.

During 2012-2013, the system modelled was run on the basis of the multirate T1 tariff, with pumping scheduled to roughly coincide with the cheaper, night-time rate. Details of the T1 tariff can be seen in Table I. Table II details the specification of the system and table II detaisl of the variables employed in the model.

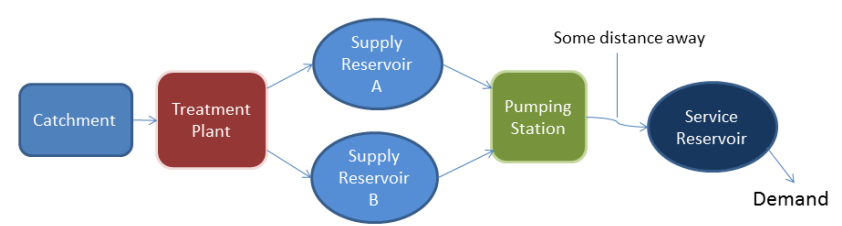

Fig. 1. Representation of water system modelled

TABLE I

T1 TARIFF DETAILS

\begin{tabular}{|l|c|}
\hline Period & $\begin{array}{c}\text { Cost } \\
(\mathbf{p} / \mathbf{k W h})\end{array}$ \\
\hline Summer Day: 0800 - 2230 & 11.22 \\
\hline Nov \& Feb Day: 0800 - 1600, 1900 - 2030 & 12.28 \\
\hline Dec \& Jan Day: 0800 - 1600, 1900 - 2030 & 14.03 \\
\hline Nov \& Feb Peak: 1600 - 1900 & 20.54 \\
\hline Dec \& Jan Peak: 1600 - 1900 & 22.18 \\
\hline $\begin{array}{l}\text { Evening \& Weekend: W/end 0800 - 2230, } \\
\text { Evening 2030 - 2230 }\end{array}$ & 10.48 \\
\hline Night: 2230 - 0800 & 7.41 \\
\hline
\end{tabular}

$i \quad$ Time period $(\mathrm{i}=1,2, \ldots 96,15 \mathrm{~min} /$ period $)$

$C_{i} \quad$ Electricity cost, $i^{t h}$ period

$W_{i} \quad$ Wind generation as $\%$ of total in $i^{t h}$ period

$F \quad$ Pump flow rate per period

$M_{i} \quad$ Power cost per unit, $i^{t h}$ period

$D_{i} \quad$ Demand from service reservoir, $i^{t h}$ period

$T_{i} \quad$ Flow into supply reservoir, $i^{\text {th }}$ period

$O_{i} \quad$ Pump switch coefficient, $i^{\text {th }}$ period (1 or 0 )

$P \quad$ Pump power consumption

$R_{i} \quad$ Service reservoir water volume, $i^{t h}$ period

$S_{i} \quad$ Supply reservoir water volume, $i^{\text {th }}$ period

$x \quad$ pump status ( 1 or 0 )

TABLE II

SYSTEM SPECIFICATIONS

$\begin{array}{lc}\text { Parameter } & \text { Value } \\ \text { Pump power consumption (kW) } & 243 \\ \text { Pump flow rate (1/s) } & 150 \\ \text { Service reservoir capacity (Ml) } & 11.5 \\ \text { Service reservoir min. volume (Ml) } & 4.9 \\ \text { Supply res. A capacity (Ml) } & 13.5 \\ \text { Supply res. A Min. volume (Ml) } & 8.9 \\ \text { Supply res. B capacity (Ml) } & 6.75 \\ \text { Supply res. B Min. Volume (Ml) } & 4.45 \\ \text { Approx. daily demand (Ml) } & 6\end{array}$

\section{A. Scenarios}

Three scenarios were investigated for each of the three years modelled:

1) EA1 - Optimising the pumping schedule on the basis of EA1 SMP and calculating costs using the ex-post SMP, EP2

2) Perfect Forecasting (PF) - Optimising the pumping schedule on the basis of EP2 and calculating costs using the same

3) T1 Optimising on the basis of the T1 multirate tariff and calculating wholesale costs using EP2 
4) Flatrate A drain-and-refill model based on a flatrate tariff, with wholesale costs calculated based on EP2

For the period April 2012 - Mar 2013, these scenarios were also compared with data from the actual operation of the system.

\section{B. Optimisation}

The objective was to minimise electricity cost and pump switching, subject to the constraints detailed below.

- Service reservoir water volume must be between min and $\max$

- Supply reservoir water volumes must be between min and $\max$

- Water flow into supply reservoirs must be maintained at a constant rate

Since the water provided is to fill a service reservoir rather than to supply the demand, minimum pressure constraints were neglected.

\section{OPTIMISATION}

Equation 1 shows the mathematical representation of the optimisation problem.

$$
\begin{aligned}
& \text { minimise: } \Sigma C_{i} \\
& \text { subject to: } \Sigma F_{i} \geq \Sigma D_{i} \\
& R_{i}=R_{i-1}-D_{i-1}+F x_{i-1} \\
& S_{i}=S_{i-1}-F x_{i-1}+T_{i-1} \\
& C_{i}=P M_{i} x_{i} \\
& \Sigma O_{i} \leq O_{\max } \\
& \left.\begin{array}{l}
R_{\min } \leq R \leq R_{\max } \\
S_{\min } \leq S \leq S_{\max }
\end{array}\right\} \forall i
\end{aligned}
$$

\section{A. Optimisation Method}

The optimisation method used was a Genetic Algorithm (GA). These have been found to be well suited to the problem of pump switching [15] [16] [17] [18] [19].

GAs are meta-heuristic methods which initiate by randomly creating a population of potential solutions. GAs simulate the natural processes of evolution and natural selection to 'evolve' better solutions. During each iteration (generation) of the algorithm the overall fitness of the population is assessed by means of a fitness function. An individual's chance of survival is proportional to its fitness. Surviving solutions are then combined with others (crossover), akin to reproduction. Random mutation is also used to diversify the population and reduce the likelihood of convergence to a non-global optimum [20]. Mutation and crossover are controlled by predefined probabilities. There are a number of different ways of defining how many individuals survive from one generation to the next - the approach used here was to carry across only the best individual from each generation.

In the case of the pumping schedule used here, a candidate solution was a 96-digit binary string, with each digit representing one 15-minute interval. The fitness of each candidate solution was found by running a simulation of the system using that candidate's schedule. Each solution was given a 'constraint penalty' score based on the number of times it violated minimum and maximum water volume constraints. A 'switching penalty' score was also added based on the number of pump switches. The average unit cost of wholesale electricity for a given schedule was also calculated. Fitness was calculated on the basis of average unit cost of electricity and number of pump switches. The pump switch limit was set to 8 . As two pumps were always run simultaneously in the system modelled, both pumps were aggregated in the simulation. Real-life operation limits pump switching to approximately 4 switches per day per pump but it was very difficult to take advantage of price variation with such a low limit. The GA also struggled to find viable solutions with such a low number of pump switches that did not violate other constraints.

The algorithm was run for 170 generations with a population size of 400 . The probability of mutation was set at $2 \%$, while the crossover rate was set at 1 (all candidate solutions were 'bred' with each other). The fitness score formulation and model parameters were arrived at by means of an iterative process, with parameters being adjusted to reduce the number of generations required before a good solution was found.

\section{B. Model Inputs}

All inputs were at 15-minute resolution, with a corresponding 96 data points in each of the days modelled. Inputs were as follows:

- Water demand (1)

- EA1 SMP forecast (£/MWh, EA1 optimisations), T1 tariff (£/MWh , T1 optimisations)

- EP2 SMP (£/MWh)

- Wind power penetration (\%)

- Wind generation (MW)

The models were also initialised with the actual reservoir levels at 00:00 on 1 April 2012.

\section{Model Outputs}

For each day modelled, the algorithm outputs a diagram as per Fig. 2. This shows the water level in both the service and supply reservoirs. It also shows output data and the pump schedule for the day.

\section{Results}

SMP is the wholesale cost of electricity and does not take into account other costs such as transmission and distribution [21]. The T1 tariff takes all costs into account and could not itself be compared fairly with SMP. Hence, only the wholesale costs of electricity were compared. It is likely that the markup on the wholesale cost that a consumer would pay would be very similar across all scenarios. Table III shows a summary of results found from the various model runs for the total period April 2012 - March 2015. 
TABLE III

SUMmARY OF RESUlTS, APRIL 2012 - MARCH 2015

\begin{tabular}{|l|c|c|c|c|c|}
\hline Averages (/day) & Actual Operation & Flatrate & T1 & PF & EA1 \\
\hline Power consumption (kWh) & 2254.3 & 2397.7 & 2496.2 & 2498.0 & 2497.1 \\
\hline EA1 forecast (£) & - & - & - & - & 89.28 \\
\hline Final (EP2) cost & 158.14 & 166.77 & 104.89 & 121.35 & 104.78 \\
\hline Unforecast cost (£) & - & - & - & - & 15.50 \\
\hline EP2 unit cost (p/kWh) & 7.01 & 6.71 & 4.20 & 3.91 & 4.2 \\
\hline Wind, gen. (\%) & 14.56 & 17.82 & 20.09 & 20.95 & 20.41 \\
\hline Wind, consumed (\%) & 608.6 & 682.9 & 661.3 & 715.3 & 692.8 \\
\hline Wind, gen. (MW) & 4.04 & 0.99 & 4.79 & 5.79 & 5.54 \\
\hline Wind, consumed (MW) & \multicolumn{7}{|c|}{695.6} \\
\hline Pump switches &
\end{tabular}
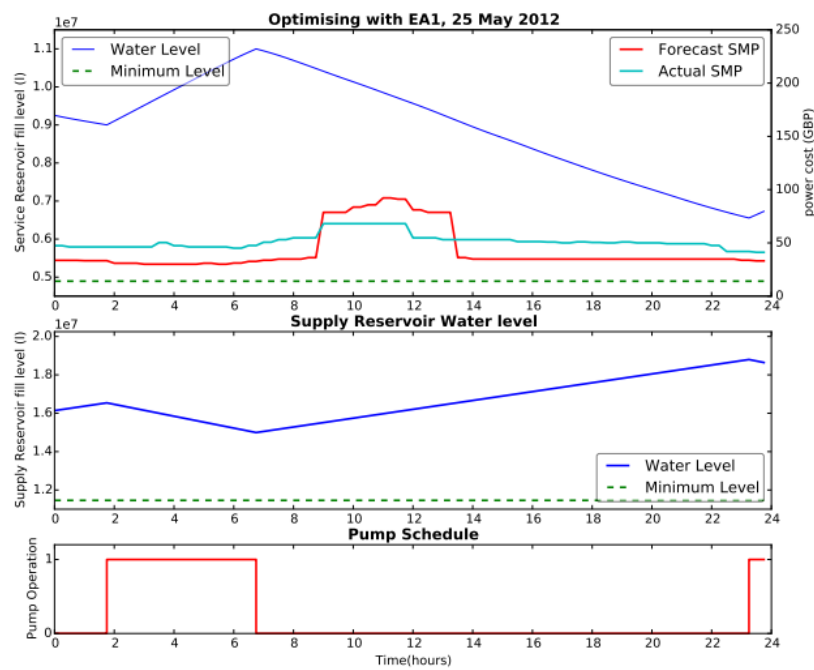

Fig. 2. GA output graph 1

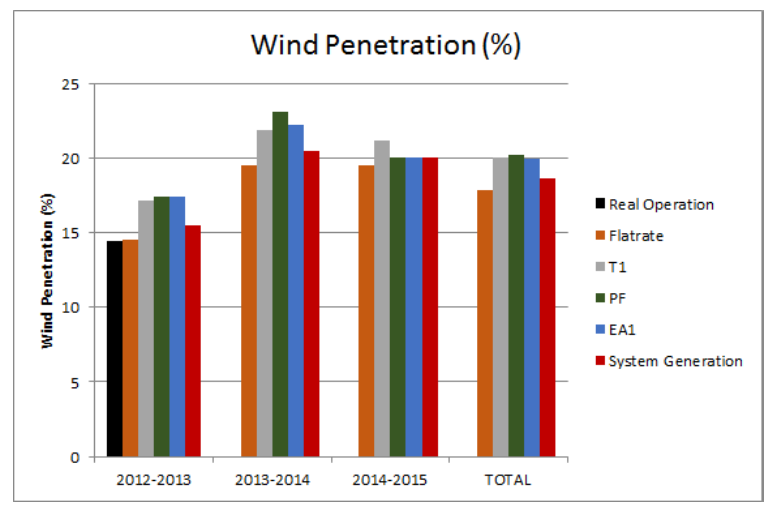

Fig. 3. Average wind power penetration, system and periods when power was consumed, all years

Actual operation data were available only for 2012 - 2013. The associated power consumption data is likely to be incorrect as it is not sufficient to meet the water demand for the period modelled. This is most likely due to errors with the SCADA system. However, it serves as a conservative estimate - since pumping is likely under-represented here, actual costs would have been higher, and thus any savings found using the optimisation detailed here would actually be greater.
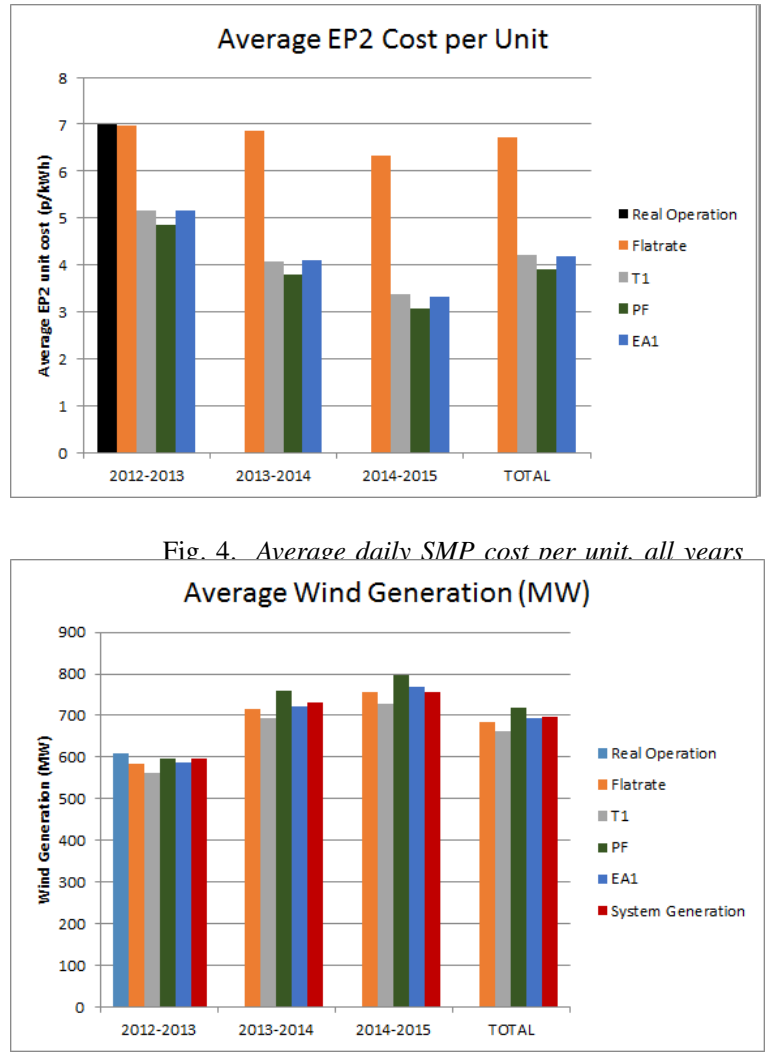

Fig. 5. Average wind generation, system and periods when power was consumed, all years

\section{A. Cost of electricity}

Table III shows that optimisation on the basis of PF SMP was cheaper than the alternative across all three years $-6.8 \%$ cheaper per unit than the T1 optimisation. EA1 optimisation was more expensive than T1 in 2012-2013 but cheaper in both other years. Flatrate optimisation was significantly more expensive than any other $-59.8 \%$ more expensive than $\mathrm{T} 1$ optimisation on average.

In 2012-2013, the only period for which actual operation data were available, the SMP unit cost of PF and EA1 optimisations were $30.7 \%$ and $26.5 \%$ cheaper respectively than actual operation. T1 optimisation was $25.9 \%$ cheaper than actual operation, showing that the rough optimisation carried out by NIW did not fully capture the potential savings possible using the T1 tariff. 


\section{B. EA1 and Forecast Accuracy}

PF optimisation was always cheaper than EA1. This is to be expected, as EP2 is the final, D+4 cost of electricity, and takes into account factors such as operational constraints that are not forecast at D-1 with EA1 [14]. An annual breakdown of average unit costs (Fig. 4) show that this was a consistent trend. EA1 forecast inaccuracy was highest in 2012-2013, with $32.3 \%$ of the EA1 cost being unforecast. This cost was much lower subsequently. EA1 and T1 optimisations had very similar costs throughout, with no more than $1 \%$ difference between the annual averages.

EA1 optimisation in 2012-2013 was cheaper than actual operation, showing that pump scheduling on the basis of the SMP forecast is a legitimate cost-saving option.

\section{Wind Power Penetration}

The average wind penetration on the system during the periods in which the pumps were operating was higher than the annual average of generated power for the PF, EA1 and $\mathrm{T} 1$ scenarios, as can be seen in fig 3. Actual operation in 2012 and flatrate optimisation across all three years showed lower average wind power penetration than the total power system average.

$\mathrm{PF}$ wind power penetration was highest overall, although EA1 wind penetration was not much lower - indeed, in 2012-13 EA1 showed higher wind power penetration - this despite the highest degree of inaccuracy in price forecasting.

SMP costs can be expected to reflect variation in wind generation, which reduces the requirement for expensive generation. However, despite the fact that the fixed schedule T1 tariff does not reflect the constant variation in wind output, the T1 optimisations showed an increased wind penetration of consumed power compared to total annual system generation. This is explained below.

The EA 1 and PF optimisations showed a significant increase in wind penetration of consumed power compared to the system average $-9.46 \%$ and $12.37 \%$ higher respectively. T1 optimisation gave a $7.58 \%$ increase in wind penetration, while flatrate wind penetration was $4.55 \%$ lower than the power system average. This trend was the same across all three years, as can be seen in fig 3 - EP2 showed the highest uptake, followed by PF and T1. Despite the inaccuracy of EA1 forecasting, it still allowed for a significant increase in the uptake of wind power, with a much smaller margin between the EA1 and PF wind penetration than there was between the system average and PF.

\section{Wind Power Magnitude}

As well as the penetration of wind power in periods during which the pumps were running, the average magnitude of wind generation (in MW) during these periods was also measured. None of the optimisations carried out showed a significant increase in this figure compared to the power system average, as can be seen in Table III and Fig. 5. Barring T1, all optimisations gave average wind power magnitudes within $2 \%$ of power system average wind generation. The high wind penetration yet comparatively low wind power magnitude associated with the T1 optimisations can be partially explained by the fact that T1 optimisation favours night-time operation, where total demand is low and so the proportion of the demand served by wind is higher. For the period 2012-2015, wind generation was approximately $5.3 \%$ less at night than on average - however, night-time demand was $19.5 \%$ lower than average. Wind Penetration averaged $20.4 \%$ at night, compared to a total average of $18.64 \%$.

\section{CONCLUSION}

The SMP-based GA-optimised pump schedules showed significant potential cost savings for NIW. Perfect foresight optimisation gave the highest potential savings, with wholesale costs $30.7 \%$ cheaper for the period 2012-13 than actual operation, and $9.83 \%$ cheaper than optimisation based on the T1 tariff. This figure would not be attainable in actual operation as the EP2 cost is not known until four days after the trading day (D+4). A schedule based on the D-1 EA1 forecast price of SMP still gave $26.5 \%$ saving over actual operation in 2012-13, despite underestimating the EP2 cost by $24.4 \%$. The electricity cost of EA1 optimisation was not significantly different to T1 optimisation across all three years investigated, but gave a higher uptake of wind generation. Running the system on a flatrate tariff was significantly more expensive than any other scenario modelled as it did not take into account any price variation.

It should be noted that the EA1 forecast is only the first available forecast of SMP for a given day. A more accurate EA2 forecast is published later on D-1, as well as a withinday forecast on the day itself. These are both more accurate than the EA1 forecast. EA1 therefore represents a worst-case scenario for price forecasting, yet gave costs no worse than the $\mathrm{T} 1$ scenario. If the pumping schedule produced by the EA1 optimisation were updated when updated price forecasts became available, it is likely that the costs would be closer to those seen in the PF scenario.

Optimisation on the basis of energy cost meant that the pumps consumed power during periods where wind penetration was higher than average (In the case of the T1 optimisation, this was due to the higher than average wind penetration at night). However the magnitude of wind generation was not significantly higher than average during periods when the pumps were running compared to the power system average. This suggests that wind power penetration has a more significant depressant effect on SMP than wind power magnitude. Wind power is not the only factor which would decrease SMP - low demand also correlates with low wholesale prices. Therefore, it is likely that SMP-based optimisation of electricity demand in the SEM would allow increased penetration of wind generation during low-load periods, while not necessarily promoting the overall level of wind generation. This could be used to reduce the requirement for curtailment by increasing the SNSP limit. 
However, it is likely that large scale application of SMP-based DSM would have an effect on the SMP itself.

It should be noted that this approach is not exclusive to water pumping - RTP/SMP based DSM of any loads would have a similar outcome.

\section{REFERENCES}

[1] Finn, P. et al.; "Increased Penetration of Renewable Energy using Demand Side Management: Immersion Heater Analysis", International Conference on Renewable Energies and Power Quality, Granada (Spain), 23-25 March 2010

[2] European Environment Agency, "Europe's onshore and offshore wind energy potential", Technical report No 6/2009, June 2009

[3] EirGrid, "All-Island Generation Capacity Statement 2015 - 2024"

[4] P. Finn, C. Fitzpatrick, M. Leahy, and L. Relihan, Promotion of wind generated electricity using price responsive demand side management: Price prediction analysis for imperfect energy storage, in Proc. 2010 IEEE Int. Symp. Sustainable Systems and Technology (ISSST), 2010, pp. 15

[5] McGarrigle, E.V. et al; "How much wind energy will be curtailed on the 2020 Irish power system? Journal of Renewable Energy, vol 55, 2013, pp 544-553

[6] Soni, 'DS3 Programme', [online], http://www.soni.ltd.uk/Operations/sg/ DS3/ http://www.soni.ltd.uk/Operations/sg/DS3/

[7] Almenta, M.M. et al.; "A smart load appliance application using a single compressor fridge-freezer to support grid operations",P ower Engineering Conference (UPEC), 2014 49th International Universities, Cluj-Napoca, Romania, 2-5 September 2014

[8] Keane, A., et al.; "Demand side resource operation on the Irish power system with high wind power penetration", in Journal of Energy Policy Volume 39, Issue 5, May 2011, pp 2925

[9] EPRI, "Water \& Sustainability (Volume 4): U.S. Electricity Consumption for Water Supply \& Treatment - The Next Half Century", Tech. Report, 2010

[10] Bingham, I, Response to enquiry, ref NIW 1415272, Northern Ireland Water, 2014

[11] Ormsbee, L.E., Lansey, K.E.; “Optimal Control of Water Supply Pumping Systems", Journal of Water Resources Planning and Management, ASCE, $120(2), 237$

[12] Kernan, R. et al.; "Demand Side Management of Public Clean Water Supply", Power Engineering Conference (UPEC), 2015 50th International Universities, Stoke-on-Trent, UK, 1-4 September 2015

[13] P. Finn et al.; "Increased Penetration of Wind Generated Electricity using Real time Pricing \& Demand Side Management", IEEE International Symposium on Sustainable Systems and Technology, May 2009, pp. 1-6

[14] "CER Factsheet on the Single Electricity Market", Commission for Energy Regulation, 2011. Available online: https://www.cer.ie/docs/000262/ cer11075.pdf

[15] X. Zhuan, X. Xia, "Optimal operation scheduling of a pumping station with multiple pumps", Applied Energy 104, 2013, pp250-257

[16] B. Coelho et al., "Analysis of diverse optimisation algorithms for pump scheduling in water supply systems", 3rd International Conference on Engineering Optimization, Rio de Janeiro, Brazil, July 2012

[17] M. López-Ibáñez et al., "Optimal Pump Scheduling: Representation and Multiple Objectives”, CEC, Napier University, Edinburgh, Scotland, 2012

[18] D.F. Moreira, H.M. Ramos, "Energy Cost Optimization in a Water Supply System Case Study", Hindawi Journal of Energy, V. 2013

[19] H.M. Ramos et al., "Energy Efficiency in Water Supply Systems: GA for Pump Schedule Optimization and ANN for Hybrid Energy Prediction", Water Supply System Analysis - Selected Topics, 2012

[20] M. Mitchell, "An Introduction to Genetic Algorithms", MIT Press, 1996

[21] "CER Factsheet on Electricity Prices in Ireland", Commission for Energy Regulation, 2011. Available online: https://www.cer.ie/docs/000262/ cer10062.pdf 